\title{
Milk fatty acid composition as an indicator of energy status in Holstein dairy cows
}

\author{
Lana Vrankovié ${ }^{1}$, Jasna Aladrović ${ }^{1}$, Daria Octenjak ${ }^{2}$, Dušanka Bijelić ${ }^{2}$, Luka Cvetniće ${ }^{2}$, and \\ Zvonko Stojević ${ }^{1}$ \\ ${ }^{1}$ Department of Physiology and Radiobiology, University of Zagreb Faculty of Veterinary Medicine, \\ Heinzelova 55, 10000 Zagreb, Croatia \\ ${ }^{2}$ Students of Faculty of Veterinary Medicine, University of Zagreb, Heinzelova 55, 10000 Zagreb, Croatia \\ Correspondence to: Lana Vranković (lana.vrankovic@vef.hr)
}

Received: 26 January 2017 - Revised: 9 June 2017 - Accepted: 19 June 2017 - Published: 20 July 2017

\begin{abstract}
Transition dairy cows often enter a stage of negative energy balance during which the utilization of energy reserves is reflected in the milk fatty acid (FA) composition. In this study, metabolic status was evaluated by measuring milk FA, ruminal short-chain FA (RSCFA), and serum biochemical parameters in Holstein cows. Samples (milk, rumen contents, and blood) were collected around days 30 (early) and 150 (middle) of lactation, and rumen contents and blood samples were collected 30 days before calving (dry). Fatty acids were extracted and FA composition was determined. Glucose, triacylglycerols, total cholesterol, low-density lipoprotein cholesterol (LDL-C) and high-density lipoprotein cholesterol (HDL-C), beta-hydroxybutyric acid (BHB), and non-esterified fatty acid (NEFA) concentrations were determined in serum samples. Lower percentages of saturated FA in milk and higher percentages of monounsaturated FA, polyunsaturated FA, and C18:1n-9 were observed in early lactation compared to mid-lactation. In rumen higher concentrations of propionic acid were determined at mid-lactation compared to early lactation. Acetic and butyric acid concentrations showed no significant differences between sampling intervals. In serum higher glucose concentrations were observed during the dry period and mid-lactation than during early lactation. Lower BHB and higher NEFA concentrations were noted during early lactation compared to mid-lactation and the dry period. Total cholesterol, LDL-C, HDL-C and triacylglycerols showed no significant differences between sampling intervals. The results of the present study suggest that determination of milk FA is a potential indicator of energy status in dairy cows.
\end{abstract}

\section{Introduction}

Ruminal short-chain fatty acids (RSCFAs) are produced in the rumen of the cow through the microbial fermentation of carbohydrates and protein. They are subsequently absorbed through all compartments of the stomach (Leek, 2004). Acetic, propionic, and butyric acids are the predominant RSCFAs in rumen fluid. Concentrations and relative proportions of RSCFAs are associated with the level and composition of feed intake (Murphy et al., 1982). Ruminal short-chain fatty acids constitute the major source of energy in ruminants, providing $50-80 \%$ of the total amount of digested energy (Thomas, 2012) and, thus, are of great importance in the production of milk in dairy cows. Both the total yield of RSCFAs and the types of RSCFAs formed can sig- nificantly affect the utilization of absorbed nutrients in dairy cows, and can thus considerably affect milk volume and composition (Butler et al., 2008).

The peripartal period is the most demanding in terms of herd health management (Walsh et al., 2011; Fiore et al., 2014, 2015). The increased energy demands of foetal development and milk production are evident in transition dairy cows (Arfuso et al., 2016). Therefore, cows often enter a stage of negative energy balance (Walsh et al., 2011). The most important aspect in the assessment of energy status is centred on the determination of blood non-esterified fatty acids (NEFAs) and beta-hydroxybutyrate (BHB) levels (LeBlanc, 2010). NEFA levels can be increased through increased mobilization of stored lipids, which can thereby 
indicate metabolic disorders, such as ketosis and fatty liver syndrome (Duffield et al., 1998; Fiore et al., 2017). The first measurable indicator of ketogenesis is an increase in BHB concentration in the blood (Payne and Payne, 1987; Schulz et al., 2014) The utilization of energy reserves is also reflected in the milk fat content (Bauman et al., 2006), namely in the fatty acid (FA) composition and mutual ratios between individual FA groups (Ducháček et al., 2014). Milk FA and protein contents are correlated with metabolic status (Mulligan et al., 2006); therefore, measurement of these two parameters is usually recommended for the determination of negative energy balance (Gross et al., 2011). Several researchers (Berry et al., 2006; Soyeurt et al., 2006; Bastin et al., 2011) have determined the FA composition of milk to predict energy status.

It is well known that the utilization of fat reserves during the transition period affects the FA composition of milk. Currently, data on the RSCFA content and FA composition of milk as indicators of energy metabolism in Holstein dairy cows are scarce. The collection of milk samples is more easily obtained and is more suitable in terms of animal welfare considerations. Therefore, the aim of this study was to evaluate the energy status of Holstein dairy cows during different stages of lactation by investigating the milk FA composition, the RSCFA concentration, and serum biochemical parameters.

\section{Material and methods}

This study was approved by the Ethics Committee of the Faculty of Veterinary Medicine (251-61-01/139-13-2; 251-6101/139-16-3).

\subsection{Animals and diets}

Prior to the selection of cows for this study, we contacted government authorities to get the list of farms. Afterwards, we contacted farm owners to ask whether they were willing to accept our research on their farm. After that we carried out a survey where we asked the owners about the number of animals on the farm, feeding regime, management system, and production of animals. Based on the survey results, we selected a farm which was acceptable for our research goals. The selected farm properly kept records about animals and comprised around 100 cows of Holstein breed. The selected farm was located near the town of Đakovo, Croatia $\left(45^{\circ} 18^{\prime} 35.989^{\prime \prime} \mathrm{N}, 18^{\circ} 24^{\prime} 35.215^{\prime \prime}\right.$ E). Twelve Holstein cows aged 2.5-7.8 years during lactations ranging from the first to the seventh were selected for the study. Selected cows were in a production phase acceptable for this research and were uniform depending on production phase as well as clinically healthy. Average body mass of cows was $680 \pm 42 \mathrm{~kg}$ and body score condition (BSC) was as follows: in the dry period $(3.42 \pm 0.47)$, around days 30 and 150 of lactation $(2.83 \pm 0.51,3.10 \pm 0.45$, respectively). Cows were kept freely in stalls without pasture. Data on milk compo-
Table 1. Composition of daily meal of Holstein cows based on production cycle.

\begin{tabular}{lr}
\hline Composition of food before calving & Amount $(\mathrm{kg})$ \\
\hline Straw & 1.5 \\
Hay & 2.3 \\
Beet pulp & 5.0 \\
Corn silage & 12.0 \\
Corn maize & 0.5 \\
Mineral-vitamin and energy supplements & 5.4 \\
\hline Composition of food 30 days after calving & \\
\hline Hay & 4.5 \\
Beet pulp & 10.0 \\
Corn silage & 24.0 \\
Corn maize & 1.0 \\
Mineral-vitamin and energy supplements & 11.7 \\
\hline Composition of food 150 days after calving & \\
\hline Straw & 0.5 \\
Hay & 4.0 \\
Beet pulp & 10.0 \\
Corn silage & 25.0 \\
Mineral-vitamin and energy supplements & 11.8 \\
\hline
\end{tabular}

sition and average milk production were obtained through the Croatian Agricultural Agency. Feed composition of the diet fed to the subjects of the study is shown in Table 1 . The following mineral-vitamin and energy supplements administered to the subjects all had protected formulas: Rindamin MF Sauer, Schaumann energy (Schaumann Agri Ltd., Koprivnica, Croatia, respectively), Mycostop (INBERG Ltd., Belgrade, Serbia), Bovi top Elevate (Alltech, Dunboyne, Ireland), and glycerol. All animals were clinically healthy during the study.

\subsection{Sampling and preparation of samples for analysis}

The composite milk samples (pool of four quarters of the udder) were first collected in tubes, twice during the lactation period, around days 30 and 150 , and stored at $-20^{\circ} \mathrm{C}$ until analysis. Samples of rumen contents and blood were collected 30 days before delivery and around days 30 and 150 of lactation. The rumen contents were sampled using a rumen fluid collector. First, $100 \mathrm{~mL}$ was discarded and the next $50 \mathrm{~mL}$ was stored in Falcon ${ }^{\circledR}$ tubes and immediately frozen in liquid nitrogen. Blood was sampled via jugular venepuncture into BD Vacutainer ${ }^{\circledR}$ tubes (BD Diagnostics, Plymouth, UK). After centrifugation at $1600 \times g$ for $20 \mathrm{~min}$ at $20^{\circ} \mathrm{C}$, blood serum samples were separated and stored at $-20^{\circ} \mathrm{C}$, until analysis. All samples were analysed within 2-3 months after collection. 
Table 2. Average milk production around days 30 and 150 of standard lactation and milk fat and protein percentage in Holstein cows.

\begin{tabular}{lrrrr}
\hline & \multicolumn{2}{c}{ Average milk production and composition (kg) } & \\
\cline { 2 - 4 } & Day 30 (approx.) & Day 150 (approx.) & SEM & $P$ value \\
\hline Milk production (kg) & 40.14 & 32.65 & 2.36 & 0.002 \\
Milk fat (\%) & 3.16 & 3.44 & 0.23 & 0.446 \\
Protein (\%) & 2.97 & 3.35 & 0.09 & 0.011 \\
\hline
\end{tabular}

Results presented as mean \pm SEM.

\subsection{Milk fatty acid analysis}

Milk fat was extracted by the standard procedure of Hara and Radin (1978) using the solvent mixture of isopropanol and hexane in a ratio of $3: 2$. The FAs were converted to methyl esters via trans-esterification with a $20 \%$ solution of boron trifluoride in methanol (Rule, 1997). Fatty acid composition was determined using a Shimadzu GC2010 Plus gas chromatograph (Shimadzu, Kyoto, Japan) equipped with a flame ionization detector and a ZB-WAX column $(30 \mathrm{~m}$ length, Phenomenex, Torrance, CA, USA). The chromatographic conditions were as follows: carrier gas, helium; injection volume, $1 \mathrm{~mL}$; injector temperature, $250^{\circ} \mathrm{C}$; detector temperature, $300^{\circ} \mathrm{C}$; oven temperature programme, initially $60^{\circ} \mathrm{C}$, then increased at $13{ }^{\circ} \mathrm{C} \mathrm{min}^{-1}$ to $150^{\circ} \mathrm{C}$, at $2{ }^{\circ} \mathrm{C} \mathrm{min}^{-1}$ to $220^{\circ} \mathrm{C}$, and at $2^{\circ} \mathrm{C} \mathrm{min}^{-1}$ to $240^{\circ} \mathrm{C}$. All experimental measurements were repeated three times and the average values were reported. Quantification was determined through area normalization, with an external standard mixture of fatty acid methyl esters (Sigma-Aldrich, Steinheim, Germany). Fatty acid composition was calculated as the percentage of each individual fatty acid relative to the total fatty acids.

\subsection{Rumen fatty acid analysis}

To determine RSCFAs, approximately $1 \mathrm{~g}$ of thawed digesta was diluted with $1 \mathrm{~mL}$ of ultrapure water and centrifuged. After centrifugation $(10 \mathrm{~min}$ at $5000 \times g)$, the supernatant was transferred to another tube, and $0.2 \mathrm{~mL}$ of $24 \%$ metaphosphoric acid was added. The sample was then placed in an ice bath to allow the protein to settle completely. Finally, samples were centrifuged $\left(10 \mathrm{~min}\right.$ at $\left.5000 \times g, 20^{\circ} \mathrm{C}\right)$ and the clear supernatant was analysed. The supernatants were analysed to determine the concentrations of acetic, propionic, and butyric acids, using a Shimadzu GC2010Plus gas chromatograph (Shimadzu, Kyoto, Japan), equipped with a model AOC 20i auto injector, a flame ionization detector (FID) and a Nukol ${ }^{\mathrm{TM}}$ column $(30 \mathrm{~m} \times 0.25 \mathrm{~mm} \times 0.25 \mu \mathrm{m})$ (Supelco, Bellefonte, PA, USA). The chromatographic conditions employed were as follows: carrier gas, helium; split ratio, 1:100; injection volume, $1 \mu \mathrm{L}$; injector temperature, $220^{\circ} \mathrm{C}$; detector temperature, $230^{\circ} \mathrm{C}$; oven temperature programme, initially $100^{\circ} \mathrm{C}$ and increased at $20^{\circ} \mathrm{C} \mathrm{min}^{-1}$ to $140^{\circ} \mathrm{C}$, and at $8^{\circ} \mathrm{C} \mathrm{min}^{-1}$ to $200^{\circ} \mathrm{C}$. Crotonic acid was used as the internal standard.

\subsection{Serum biochemical analysis}

Concentrations of the following serum biochemical parameters were determined using commercial reagents and a SABA 18 biochemistry analyser (Analyzer Medical System, Rome, Italy): triacylglycerols, total cholesterol, low-density lipoprotein cholesterol (LDL-C), high-density lipoprotein cholesterol (HDL-C), glucose, NEFAs, BHB, and activities of gamma-glutamyltransferase (GGT), aspartate aminotransferase (AST), alanine aminotransferase (ALT), and alkaline phosphatase (ALP).

\subsection{Statistical data analysis}

Cows were grouped according to the lactation period (days 30 and 150 of lactation and the dry period). Results are presented as arithmetic means \pm SEM. The normality of distribution was checked using the Shapiro-Wilk $W$ test. For cases in which the data were not normally distributed, the Box-Cox transformation was used. The significance of differences between groups was checked using repeated measured analysis of variance and the Tukey's HSD test. Differences were considered statistically significant at $P \leq 0.05$. Statistical analysis was performed using the statistical software package Statistica, version 12 (StatSoft, Inc., Tulsa, OK, USA).

\section{Results}

The average daily production, milk fat, and protein in $1 \mathrm{~kg}$ of milk around days 30 and 150 of lactation are shown in Table 2. A significantly higher percentage of protein was detected in the milk of cows around day 150 compared to day 30 of lactation $(P=0.01)$. However, no significant differences were observed in the milk fat percentage $(P>0.05)$. In Table 3 it can be seen that the most prevalent FAs around days 30 and 150 of lactation were SFAs, with palmitic acid being the most common (C16:0). Fatty acids with one double bond, or monounsaturated fatty acids (MUFAs), were the second most represented, with oleic acid (C18:1n-9) showing 
Table 3. Distribution of milk fatty acids (\%) around days 30 and 150 of lactation in Holstein cows.

\begin{tabular}{lrrrr}
\hline & Day 30 & Day 150 & SEM & $P$ value \\
\hline SFA & 63.05 & 65.28 & 0.48 & 0.001 \\
Palmitic acid & 35.92 & 37.71 & 0.27 & 0.001 \\
(C16:0) & & & & \\
MUFA & 26.93 & 24.35 & 0.42 & 0.001 \\
Oleic acid & 22.67 & 19.61 & 0.39 & 0.001 \\
(C18:1n-9) & & & & \\
PUFA & 2.78 & 1.99 & 0.07 & 0.001 \\
Linoleic acid & 2.25 & 1.63 & 0.07 & 0.001 \\
$($ C18:2n-6c) & & & & \\
\hline
\end{tabular}

Results presented as mean \pm SEM; SFA: saturated fatty acids; MUFA monounsaturated fatty acids; PUFA: polyunsaturated fatty acids.

Table 4. Fatty acid composition (\%) of milk around days 30 and 150 of lactation in Holstein cows.

\begin{tabular}{lrrrr}
\hline & Day 30 & Day 150 & SEM & $P$ value \\
\hline C10:0 & 2.67 & 3.00 & 0.06 & 0.007 \\
C12:0 & 3.31 & 3.70 & 0.05 & 0.001 \\
C14:0 & 11.84 & 12.03 & 0.08 & 0.226 \\
C14:1 & 1.21 & 1.44 & 0.03 & 0.001 \\
C15:0 & 1.72 & 1.63 & 0.02 & 0.005 \\
C15:1 & 0.02 & 0.16 & 0.03 & 0.116 \\
C16:0 & 35.92 & 37.71 & 0.27 & 0.001 \\
C16:1 & 2.94 & 3.03 & 0.06 & 0.457 \\
C17:0 & 0.65 & 0.55 & 0.03 & 0.133 \\
C17:1 & 0.09 & 0.11 & 0.03 & 0.821 \\
C18:0 & 6.86 & 6.67 & 0.11 & 0.415 \\
C18:1n-9 & 22.67 & 19.61 & 0.39 & 0.001 \\
C18:2n-6c & 2.25 & 1.63 & 0.07 & 0.001 \\
C18:3n-3 & 0.54 & 0.36 & 0.03 & 0.001 \\
C 20:1 & 0.09 & 0.03 & 0.02 & 0.116 \\
\hline
\end{tabular}

Results presented as mean \pm SEM.

the highest percentage. The least represented were polyunsaturated fatty acids (PUFAs), with linoleic acid (C18:2n-6c) being the most common. Significantly lower percentages of C10:0, C12:0, C14:1, and C16:0 on day 30 compared to day 150 of lactation $(P=0.007,0.001,0.001$, and 0.001 , respectively) are shown in Table 4 . Significantly higher percentages of C15:0, C18:1n-9, C18:2n-6c, and C18:3n-3 were observed around day 30 compared to day 150 of lactation $(P=0.005$, $P=0.001, P=0.001$, and $P=0.001$, respectively). The FA composition of milk showed no significant differences in the levels of C14:0, C15:1, C16:1, C17:0, C17:1, C18:0, and C20:1 among the various stages of lactation $(P>0.05)$.

A significantly higher proportion of C18:1/C18:0 and higher unsaturated/saturated fatty acid (UFA / SFA) ratio around day 30 compared to day 150 of lactation $(P=0.01$ and 0.001 , respectively) are shown in Fig. 1.

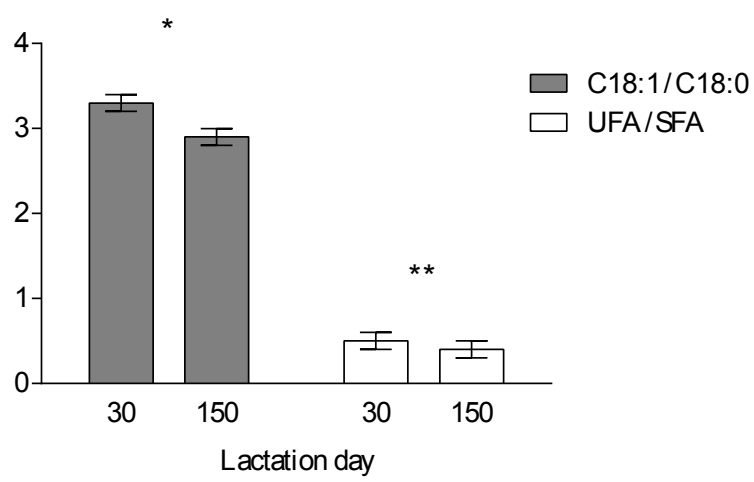

Figure 1. Ratio of C18:1 / C18:0 and UFA / SFA (unsaturated fatty acids / saturated fatty acids) in the milk of Holstein cows around days 30 and 150 of lactation; * significant difference between sampling periods at $P<0.05$; ${ }^{* *}$ significant difference between sampling periods at $P<0.01$

(a)

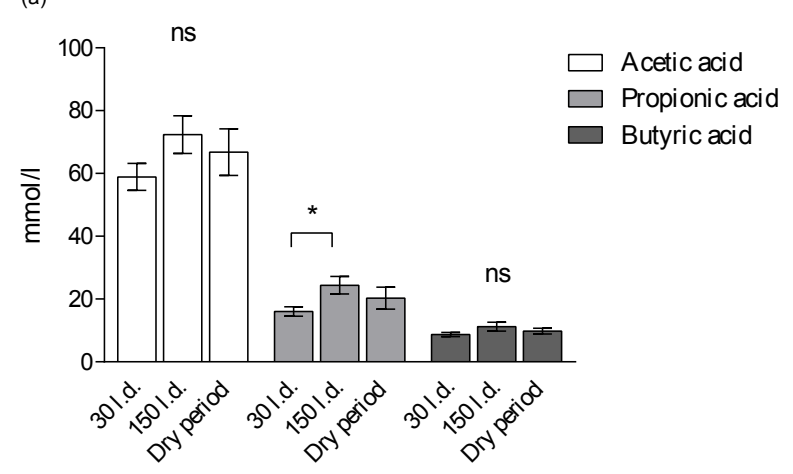

(b)

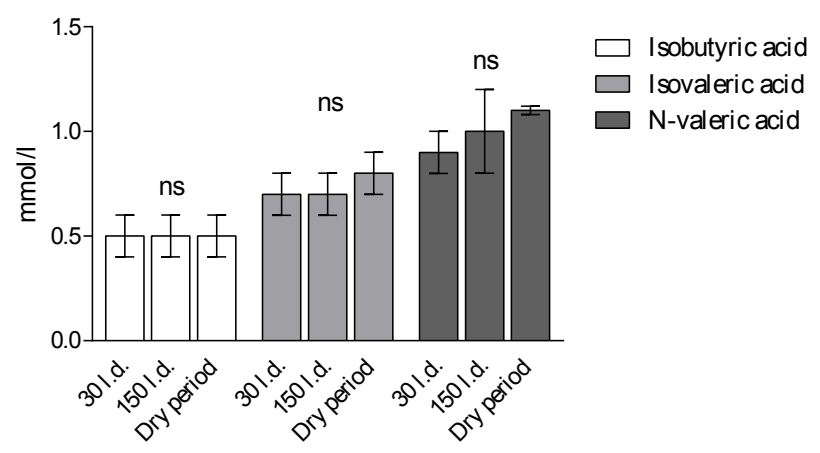

Figure 2. RSCFA concentrations in the rumen contents of Holstein cows during the production period: (a) concentrations of acetic, propionic, and butyric acids; (b) concentrations of isobutyric, isovaleric, and $n$-valeric acid. 1.d.: lactation day; ns: non-significant; * significant difference between sampling periods at $P<0.05$.

A significantly higher concentration of propionic acid around day $150(P=0.04)$ compared to day 30 of lactation is shown in Fig. 2a. Concentrations of acetic and butyric acids showed no significant differences among the periods 
(a)

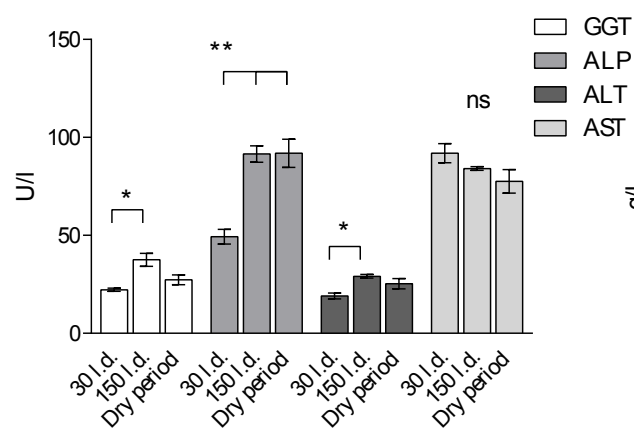

(c)

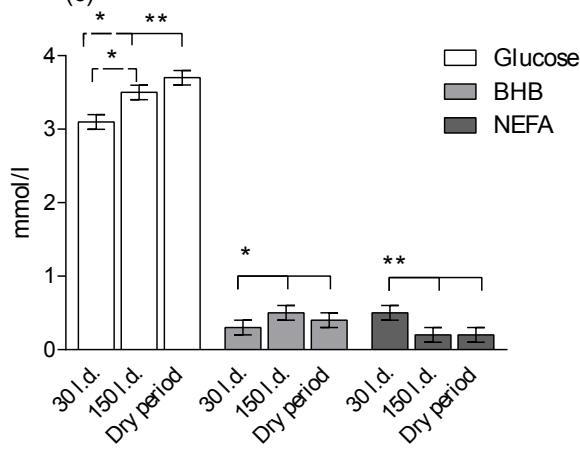

(b)

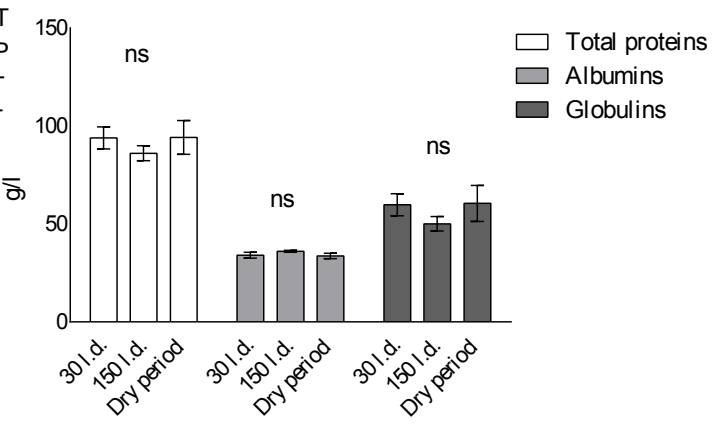

(d)

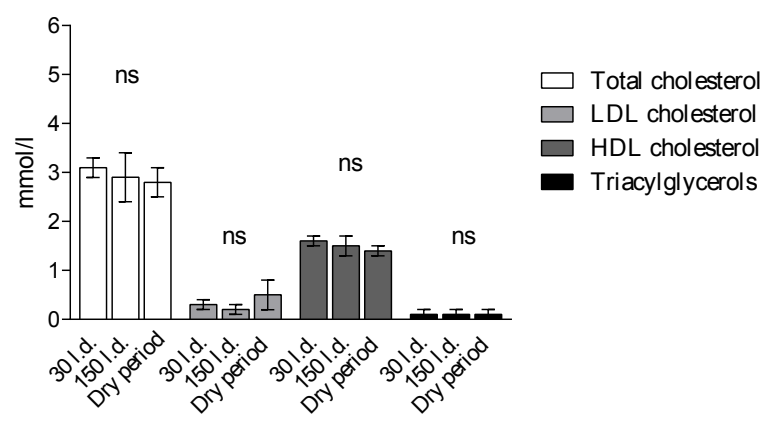

Figure 3. Serum biochemical parameters in Holstein cows during the production period: (a) activities of gamma-glutamyltransferase (GGT), aspartate aminotransferase (AST), alanine aminotransferase (ALT), and alkaline phosphatase (ALP); (b) concentrations of total proteins, albumins and globulins; (c) concentrations of glucose, beta-hydroxybutyric acid (BHB) and non-esterified fatty acids (NEFAs); (d) concentrations of total, low-density lipoprotein (LDL) and high-density lipoprotein (HDL) cholesterol, and triacylglycerols. 1.d.: lactation day; ns: non-significant; ${ }^{*}$ significant difference between sampling periods at $P<0.05$; ${ }^{* *}$ significant difference between sampling periods at $P<0.01$.

under investigation. Figure $2 \mathrm{~b}$ illustrates the concentrations of isobutyric, isovaleric, and $n$-valeric acids, with no significant differences among the periods under investigation.

Significantly higher levels of GGT $(P=0.02)$, ALP $(P=0.001)$, and ALT $(P=0.02)$ activity around day 150 compared to day 30 of lactation are shown in Fig. 3a. In addition, significantly higher ALP activity was observed around day 30 of lactation compared to the dry period $(P=0.001)$. Activity of AST showed no significant difference among the periods under investigation. The concentrations of total proteins, albumins and globulins in the serum of cows, with no significant differences among the periods under investigation, are shown in Fig. 3b. A significantly higher concentration of glucose during the dry period compared to that measured around days $30(P=0.001)$ and $150(P=0.03)$ of lactation is shown in Fig. 3c. The concentration of glucose was also significantly higher at day 150 compared to that measured at day 30 of lactation $(P=0.03)$. The concentration of BHB was significantly lower around day 30 compared to day 150 of lactation $(P=0.01)$ and during the dry period $(P=0.02)$. The serum NEFA concentration was significantly higher at day 30 of lactation compared to that measured at day $150(P=0.002)$ and during the dry pe-
$\operatorname{riod}(P=0.002)$. The concentrations of total, LDL and HDL cholesterol, and triacylglycerols, with no significant differences among the periods under investigation, are shown in Fig. 3d.

\section{Discussion}

Fatty acid composition of milk in the present study is in accordance with results obtained by Hanuš et al. (2016) for Holstein cows reared in a silage-based feeding system. In the present study, the most represented group of FAs in milk was SFAs, followed by MUFAs and PUFAs, which is consistent with the results of Stádník et al. (2015). Grummer (1991) found that cow's milk normally contains $70 \%$ SFAs, $25 \%$ MUFAs, and $5 \%$ PUFAs, whereas in the present study, the SFAs and PUFAs accounted for $64.3 \pm 1.7$ and $2.8 \pm 0.2 \%$ of the FAs, respectively. At the beginning of lactation, the majority of high-producing dairy cows are in negative energy balance, resulting in increased mobilization of adipose FAs and the incorporation of these FAs in the milk (Palmquist et al., 1993). In ruminant adipose tissue, FAs stored as triglycerides comprise mainly C16:0, C18:0, and C18:1 cis-9 (Chilliard et al., 2000). When lipolysis is 
high, the FA composition of milk has a much higher proportion of C18:0 (Barber et al., 1997). The high uptake of long-chain FAs by mammary gland tissue inhibits de novo synthesis of FAs through the inhibition of acetyl-coenzyme A carboxylase (Palmquist et al., 1993), as almost all C4:0 to C14:0 FAs and approximately half of C16:0 FAs in milk are derived from de novo synthesis (Grummer, 1991). The increase in C18:1n-9, C18:2n-6c, and C18:3n-3 in the present study indicates an increase in fat mobilization from reserves during early lactation. Lower percentages of short-chain FAs (C10:0-C16:0), as well as higher percentages of long-chain FAs, indicate negative energy balance, which is consistent with the findings of Bastin et al. (2011).

In the present study, a significantly higher percentage of SFAs around day 150 was associated with the later stages of lactation (Komprda et al., 2005), when the animals were no longer in negative energy balance (Ducháček et al., 2012; Stádník et al., 2015). Unlike the SFAs, significantly higher levels of MUFAs and PUFAs were observed around day 30 compared to day 150 of lactation. Furthermore, Stádník et al. (2015) reported a higher percentage of MUFAs during early lactation, with a gradual decline that was accompanied by a less severe negative energy balance. Lower levels of MUFAs indicate a well-balanced energy intake in cows. Reports of milk PUFA content in the literature are inconsistent. Specifically, Stádník et al. (2015) reported no significant differences in the PUFA content of milk during five lactation weeks in Czech Fleckvieh cows, whereas Bastin et al. (2011) reported that Holstein cows had a lower percentage of PUFAs in milk in early lactation. In the present study, reduced SFAs and increased MUFA + PUFA (UFA) around day 30 of lactation indicated a negative energy balance, which can lead to disturbances in the development and maturation of follicles, reduced frequency of ovulation, weaker development of the corpus luteum and a delayed onset of the sexual cycle after parturition (Tamadon et al., 2011). Furthermore, in the present study, the ratio of C18:1 / C18:0 around day 150 was 3.3 , in comparison to 2.9 around day 30 of lactation, which may indicate lower levels of desaturase activity in later lactation (DePeters et al., 1995). In the present study, a higher ratio of UFA / SFA was detected in early lactation, which may indicate a disruption in reproductive activity; Stádník et al., 2015) These results suggest the possibility of the use of FA contents in milk to monitor fertility in dairy cows.

The amounts and ratio of RSCFAs can vary, depending on the composition of the feed, extent of intestinal absorption, and the time of sampling. In the present study, animals were fed hay, haylage, silage, and a source of cellulose, which are metabolized in the rumen to acetic acid (Seymour et al., 2005). The highest concentration of acetic acid in the present study was observed around day 150 of lactation, although this was not significant. The second highest concentration was that of propionic acid and the lowest was that of butyric acid, which was consistent with RSCFA levels reported by Thomas (2012). Although not statistically significant, the highest concentration of butyric acid measured in the present study was around day 150 of lactation. A major part of the butyrate that is produced in the rumen is oxidized to BHB during absorption across the ruminal epithelium (Weigand et al., 1972; Kristensen et al., 2012), which is consistent with the results of the present study that reflected the highest BHB concentration around day 150 of lactation. When rumen fermentation declines, the absorption of butyrate across the ruminal epithelium is reduced; thus, as the epithelial formation of BHB is also reduced, this leads to lower levels in the plasma (Agenäs et al., 2003).

The most important parameters in the assessment of energy status are the levels of BHB and NEFAs in the blood (LeBlanc, 2010). Beta-hydroxybutyrate originates in the ruminal epithelium during absorption and oxidation of butyrate (Weigand et al., 1972; Kristensen et al., 2012). In the present study, the highest BHB concentration was observed around day 150 of lactation, which is consistent with the period around which the highest concentration of butyrate was observed. Blood NEFA has been shown to reflect lipolysis in cattle (Laarveld et al., 1981). When the concentration of NEFA increases, this is indicative of negative energy balance (Vernon, 2005). In this study, significantly higher concentrations of NEFA were detected around day 30 compared to day 150 of lactation and the dry period. Mobilization of fat stores in adipose tissue to provide the mammary gland with FAs for milk fat synthesis is mirrored by an increase in plasma NEFAs during feed deprivation (Agenäs et al., 2003). The higher concentration of NEFAs observed in the present study around day 30 of lactation is indicative of mild lipolysis, which is not typically followed by an increase in the levels of BHB.

\section{Conclusions}

In conclusion, the results of the present study suggest the possible use of milk FAs, particularly long-chain FAs, as indicative of energy status in dairy cows. Although milk FAs are not always fully applicable to the prediction of specific metabolic states, milk samples are more easily obtained and are more suitable with respect to animal welfare considerations.

Data availability. The original data of the paper are available upon request from the corresponding author.

Author contributions. LV carried out the research, performed the statistical analysis, analysed and interpreted the data, participated in the design of the manuscript, and gave final approval of the version to be published; JA carried out the research and contributed to conception and design of the manuscript; DO, DB, and LC contributed to design of the manuscript; and ZS revised the manuscript for critically important intellectual content and designed the research. 
Competing interests. The authors declare that they have no conflict of interest.

Acknowledgements. The results of this study were achieved through projects financed by the Ministry of Science, Education and Sports of the Republic of Croatia titled "Mineral metabolism of domestic animals in high production and stress" (053-10802292104), for which the authors express their gratitude. The authors also wish to thank Robert Martinec and Hrvoje Ciganović for assisting with sample collection.

Edited by: Manfred Mielenz

Reviewed by: two anonymous referees

\section{References}

Agenäs, S., Dahlborn, K., and Holtenius, K.: Changes in metabolism and milk production during and after feed deprivation in primiparous cows selected for different milk fat content, Livest. Prod. Sci., 83, 153-164, 2003.

Arfuso, F., Fazio, F., Levanti, M., Rizzo, M., Di Pietro, S., Giudice, E., and Piccione, G.: Lipid and lipoprotein profile changes in dairy cows in response to late pregnancy and the early postpartum period, Arch. Anim. Breed., 59, 429-434, https://doi.org/10.5194/aab-59-429-2016, 2016.

Barber, M. C., Clegg, R. A., Travers, M. T., and Vernon, R. G.: Lipid metabolism in the lactating mammary gland, Biochim. Biophys. Acta - Lipids Lipid Metab., 1347, 101-126, 1997.

Bastin, C., Gengler, N., and Soyeurt, H.: Phenotypic and genetic variability of production traits and milk fatty acid contents across days in milk for Walloon Holstein first-parity cows, J. Dairy Sci., 94, 4152-4163, 2011.

Bauman, D. E., Mather, I. H., Wall, R. J., and Lock, A. L.: Major advances associated with the biosynthesis of milk, J. Dairy Sci., 89, 1235-1243, 2006.

Berry, D. P., Veerkamp, R. F., and Dillon, P.: Phenotypic profiles for body weight, body condition score, energy intake, and energy balance across different parities and concentrate feeding levels, Livest. Sci., 104, 1-12, 2006.

Butler, S. T., Pelton, S. H., Knight, P. G., and Butler, W. R.: Follicle-stimulating hormone isoforms and plasma concentrations of estradiol and inhibin A in dairy cows with ovulatory and non-ovulatory follicles during the first postpartum follicle wave, Domest. Anim. Endocrinol., 35, 112-119, 2008.

Chilliard, Y., Ferlay, A., Mansbridge, R., and Doreau, M.: Ruminant milk fat plasticity: nutritional control of saturated, polyunsaturated, trans and conjugated fatty acids, Ann. Zootech., 49, 181-205, 2000.

DePeters, E. J., Medrano, J. F., and Reed, B. A.: Fatty acid composition of milk fat from three breeds of dairy cattle, Can. J. Anim. Sci., 75, 267-269, 1995.

Ducháček, J., Stádník, L., Ptáček, M., Beran, J., Okrouhlá, M., Č́tek, J., and Stupka, R.: Effect of cow energy status on the hypercholesterolaemic fatty acid proportion in raw milk, Czech. J. Food. Sci., 32, 273-279, 2014.

Ducháček, J., Vacek, M., Stádník, L., Beran, J., and Okrouhlá, M.: Changes in Milk Fatty Acid Composition in Relation To Indica- tors of Energy Balance in Holstein Cows, Acta Univ. Agric. et Silvic. Mendel. Brun., 1, 29-38, 2012.

Duffield, T. F., Sandals, D., Leslie, K. E., Lissemore, K., McBride, B. W., Lumsden, J. H., Dick, P., and Bagg, R.: Effect of prepartum administration of monensin in a controlled-release capsule on postpartum energy indicators in lactating dairy cows, J. Dairy Sci., 81, 2354-2361, 1998.

Fiore, E., Gianesella, M., Arfuso, F., Giudice, E., Piccione, G., Lora, M., Stefani, A., and Morgante, M.: Glucose infusion response on some metabolic parameters in dairy cows during transition period, Arch. Anim. Breed., 57, 1-9, 2014.

Fiore, E., Piccione, G., Gianesella, M., Praticò, V., Vazzana, I., Dara, S., and Morgante, M.: Serum thyroid hormone evaluation during transition periods in dairy cows, Arch. Anim. Breed., 58, 403-406, https://doi.org/10.5194/aab-58-403-2015, 2015.

Fiore, E., Piccione, G., Perillo, L., Barberio, A., Manuali, E., Morgante, M., and Gianesella, M.: Hepatic lipidosis in high-yelding dairy cows during the transition period: haematochemical and hostopathological findings, Anim. Prod. Sci., 57, 74-80, 2017.

Gross, J., van Dorland, H. A., Bruckmaier, R. M., and Schwarz, F. J.: Milk fatty acid profile related to energy balance in dairy cows, J. Dairy Res., 78, 479-488, 2011.

Grummer, R. R.: Effect of feed on the composition of milk fat, J. Dairy Sci., 74, 3244-3257, 1991.

Hara, A. and Radin, N. S.: Lipid extraction of tissues with a lowtoxicity solvent, Anal. Biochem., 90, 420-426, 1978.

Hanuš, O., Krížová, L., Samková, E., Špicka, J., Kucera, J., Klimešová, M., Roubal, P., and Jedelská, R.: The effect of cattle breed, season and type of diet on the fatty acid profile of raw milk, Arch. Anim. Breed., 59, 373-380, https://doi.org/10.5194/aab-59-373-2016, 2016.

Komprda, T., Dvořák, R., Fialová, M., Šustová, K., and Pechová, A.: Fatty acid content in milk of dairy cows on a diet with high fat content derived from rapeseed, Czech J. Anim. Sci., 7, 311319, 2005.

Kristensen, N. B., Gäbel, G., Pierzynowski, S. G., and Danfær, A.: Portal recovery of short-chain fatty acids infused into the temporarily-isolated and washed reticulo-rumen of sheep, Br. J. Nutr., 84, 477-482, 2012.

Laarveld, B., Christensen, D. A., and Brockman, R. P.: The effect of insulin on net metabolism of glucose and amino acids by the bovine mammary gland, Endocrinology, 108, 2217-2221, 1981.

LeBlanc, S.: Monitoring metabolic health of dairy cattle in the transition period, J. Reprod. Dev., 56, 29-35, 2010.

Leek, B. F.: Digestion in the Ruminant Stomach, in: Duke's Physiology of Domestic Animals, edited by: Reece, W. O., Cornell University Press, Ithaca, NY, USA, 438-474, 2004.

Mulligan, F. J., O'grady, L., Rice, D. A., and Doherty, M. L.: A herd health approach to dairy cow nutrition and production diseases of the transition cow, Anim. Reprod. Sci., 96, 331-353, 2006.

Murphy, M. R., Baldwin, R. L., and Koong, L. J.: Estimation of stoichiometric parameters for rumen fermentation of roughage and concentrate diets, J. Anim. Sci., 55, 411-421, 1982.

Palmquist, D. L., Beaulieu, A. D., and Barbano, D. M.: Feed and Animal Factors Influencing Milk Fat Composition, J. Dairy Sci., 76, 1753-1771, 1993.

Payne, J. M. and Payne, S.: The metabolic profile test, Oxford University Press, NY, USA, 1987. 
Rule, D. C.: Direct transesterification of total fatty acids of adipose tissue, and of freeze-dried muscle and liver with boron-trifluoride in methanol, Meat. Sci., 46, 23-32, 1997.

Schulz, K., Frahm, J., Meyer, U., Kersten, S., Reiche, D., Rehage, J., and Dänicke, S.: Effects of prepartal body condition score and peripartal energy supply of dairy cows on postpartal lipolysis, energy balance and ketogenesis: an animal model to investigate subclinical ketosis, J. Dairy Res., 81, 257-266, 2014.

Seymour, W. M., Campbell, D. R., and Johnson, Z. B.: Relationships between rumen volatile fatty acid concentrations and milk production in dairy cows: A literature study, Anim. Feed. Sci. Technol., 119, 155-169, 2005.

Soyeurt, H., Dardenne, P., Gillon, A., Croquet, C., Vanderick, S., Mayeres, P., Bertozzi, C., and Gengler, N.: Variation in fatty acid contents of milk and milk fat within and across breeds, J. Dairy Sci., 89, 4858-4865, 2006.

Stádník, L., Ducháček, J., Beran, J., Toušová, R., and Ptáček, M.: Relationships between milk fatty acids composition in early lactation and subsequent reproductive performance in Czech Fleckvieh cows, Anim. Reprod. Sci., 155, 75-79, 2015.
Tamadon, A., Kafi, M., Saeb, M., and Ghavami, M.: Association of milk yield and body condition score indices with the commencement of luteal activity after parturition in high producing dairy cows, Iran J. Vet. Res., 12, 184-191, 2011.

Thomas, H. H.: Gastrointestinal physiology and metabolism, in: Cunningham's Textbook of Veterinary Physiology, edited by: Klein, B. G., Elsevier, Health Sciences Division, PA, USA, 305382, 2012.

Vernon, R. G.: Lipid metabolism during lactation: a review of adipose tissue-liver interactions and the development of fatty liver, J. Dairy Res., 72, 460-469, 2005.

Walsh, S. W., Williams, E. J., and Evans, A. C. O.: A review of the causes of poor fertility in high milk producing dairy cows, Anim. Reprod. Sci., 123, 127-138, 2011.

Weigand, E., Young, J. W., and McGilliard, A. D.: Extent of butyrate metabolism by bovine ruminoreticulum epithelium and the relationship to absorption rate, J. Dairy Sci., 55, 589-597, 1972. 